\title{
The Revised Self-Care of Heart Failure Index — a new tool for assessing the self-care of Polish patients with heart failure
}

\author{
Natalia Świątoniowska-Lonc', Jacek Polański², Iwona Pilarczyk-Wróblewska², Beata Jankowska-Polańska \\ 'Department of Clinical Nursing, Faculty of Health Science, Wroclaw Medical University, Wrocław, Poland \\ 2Department of Internal Medicine, Occupational Diseases, Hypertension and Clinical Oncology, Wroclaw Medical University, Wrocław, Poland \\ ${ }^{3}$ Department of Paediatrics, Faculty of Health Science, Wroclaw Medical University, Wrocław, Poland
}

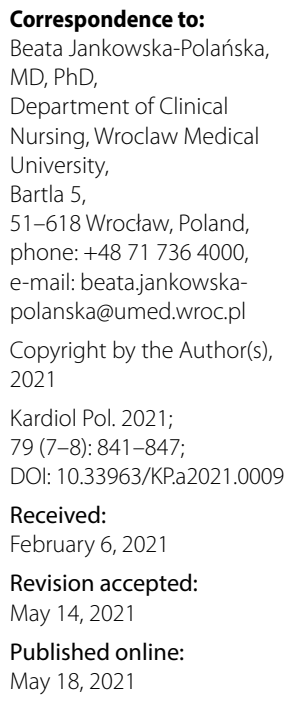

\begin{abstract}
A B S T R A C T
Background: According to the European Society of Cardiology guidelines, self-care is a key part of treatment for patients with heart failure. A large evidence base has been accumulated regarding the direct impact of self-care on the outcomes of patients with heart failure. In order to assess self-care in patients with heart failure and to evaluate the effectiveness of the interventions taken, a reliable and culturally acceptable instrument is required. The Revised Self-Care of Heart Failure Index (SCHFI) is a new tool for assessing self-care in patients with heart failure.
\end{abstract}

Aims: Our aim was to test the reliability of the Polish version of the Revised SCHFI.

Methods: The standard forward-backward translation procedure was used to translate the Revised SCHFI questionnaire into Polish. The reliability of the SCHFI was assessed based on Cronbach's a, item-total correlation, exploratory factor analysis, and confirmatory factor analysis.

Results: A total of 127 patients with heart failure (mean [SD] age, 68.5 [11.2] years) completed the questionnaire. The mean (SD) total self-care score in the study group was 51.92 (22.0). Patients scored the highest in terms of self-care confidence (mean [SD] score, 65.63 [21.0] points), and the lowest in symptom perception (mean [SD] score, 54.64 [18.28] points). The Revised SCHFI had satisfactory psychometric properties in all subscales (self-care maintenance $a=0.790$, symptom perception $a=0.790$, self-care management $a=0.705$ ).

Conclusion: The Polish version of the Revised SCHFI is a reliable and valid instrument for assessing self-care level in heart failure patients.

Key words: assessment, heart failure, psychometrics, Revised Self-Care of Heart Failure Index, self-care

Kardiol Pol 2021; 79, 7-8: 841-847

\section{INTRODUCTION}

Depending on the diagnostic criteria used and the study population, heart failure incidence is $100-900$ cases per 100000 person-years [1]. Despite advances in heart failure diagnosis and treatment, one in two patients globally is rehospitalized within 6 months of discharge, and approx. 300000 patients die annually due to heart failure decompensation [2,3]. Poor self-care capabilities and non-adherence to treatment are the primary causes of mortality and rehospitalization in heart failure patients [4].

Self-care is an important part of heart failure management [5-7]. Riegel et al. define self-care in heart failure as a naturalistic decision-making process that influences the actions that maintain physiological stability (maintenance), and facilitate the perception of symptoms (symptom perception) and response to symptoms (management) when they occur. Confidence in one's ability to perform self-care can improve both self-care maintenance and management [8]. Self-care maintenance activities include daily weighing, salt and fluid intake monitoring, and daily exercise. Self-care management activities may include the following decisions: salt and fluid intake restriction, medication (diuretic) dosage increase, and consultation with a nurse or physician.

One of the most commonly used self-care assessment instruments globally is the Self-Care of Heart Failure Index (SCHFI) [9]. The questionnaire is based on the middle-range theory of self-care of chronic illness, which addresses the process of maintaining health through health-promoting practices. Its key concepts include self-care maintenance, 
WHAT'S NEW?

This study was the first attempt at a cross-cultural adaptation of the Revised Self-Care of Heart Failure Index for the use in Polish patients with heart failure. The Revised Self-Care of Heart Failure Index has 3 scales measuring the 3 concepts of the theory: Self-Care Maintenance, Symptom Perception, and Self-Care Management. This study is a precursor to further studies examining the influence of using the Polish version of The Revised Self-Care of Heart Failure Index to monitor and identify areas of self-care teaching and counselling among Polish heart failure patients.

monitoring, and management. The original questionnaire was later modified several times in order to improve its psychometric properties, to ensure that the measured behaviors are evidence-based, and to account for their theoretical foundation [10-14]. The revised theory differs from the original situation-specific theory of self-care in a number of aspects. In the revised theory, symptom perception includes both symptom monitoring and recognition (besides body listening, symptom interpretation, and labeling), with a stricter integration of naturalistic decision-making. In addition, autonomous (associated with non-pharmaceutical symptom control methods) and consultative self-care behaviors (pharmaceutical interventions requiring consultation with a physician) were distinguished in all three self-care processes. The Revised SCFHI the above modifications. As such, the new version comprises self-care maintenance, self-care management, and the new component of symptom perception. To date, the questionnaire has been validated in an Italian patient population $[13,15]$.

In Poland, self-care in heart failure patients has so far been measured using the European Heart Failure Self-Care Behavior Scale (EHFSc-9) [16]. Due to the need to systematically evaluate self-care capabilities in the Polish setting and to implement a useful and reliable research instrument for this purpose, we have decided to perform the translation and cross-cultural adaptation of the Revised SCFHI into Polish, and to evaluate its inter-observer reliability and temporal stability.

\section{METHODS}

The current research has a cross-sectional, observational design. Data was collected from October 2019 to December 2020.

Two hundred and three patients treated at the cardiology department of the University Hospital in Wroclaw (Poland) were recruited. Out of the 203 patients, 53 did not meet the inclusion criteria or declined to participate, 23 dropped out without providing a reason, despite having previously consented to participate. Thus, the final study group included 127 patients diagnosed with heart failure and who were receiving medication. The patients completed the questionnaire on paper during their control visits. The patients received information about the aim of the study and could ask questions when filling out the questionnaire. The study was implemented by a properly trained team including a physician specializing in internal medicine and an internal medicine nurse. The personnel were informed about the aim of the study. A study protocol was prepared for the purpose of the study so that the personnel could collect data in the same way. Socio-demographic and clinical data was collected by the personnel. Finally, 127 patients have completed the study.

\section{Inclusion and exclusion criteria}

The inclusion criteria were as follows: age $\geq 18$ years, heart failure diagnosed in accordance with the European Society of Cardiology criteria [6], cognitive status allowing the study to be understood and the surveys to be completed without assistance (Mini Mental State Examination score $\geq 18$ ), and command of Polish allowing the patient to understand the questionnaire items.

Exclusion criteria were as follows: concurrent cancer, psychological disorders (such as cognitive impairment [MMSE <18] and pharmacologically treated severe depression), heart failure exacerbation, ischemic heart disease exacerbation, and acute respiratory disease (requiring urgent and intensive treatment at an Intensive Care Unit), due to the complexity of such patients' clinical status and risk of comorbidities interfering with the self-care level evaluation; lack of consent to participate; or withdrawing consent at any stage of the study.

\section{The Self-Care of Heart Failure Index $\mathbf{v} 7.2$}

The revised SCHFI ( $v$ 7.2) is used to evaluate the level of self-care in patients with heart failure. It comprises 29 items concerning three areas of self-care - self-care maintenance, symptom perception, and self-care management. In addition, it scores the level of self-care confidence, which is not a component of self-care, but has a powerful influence on it.

The Revised SCHFI uses Likert-type response options. The self-care maintenance domain includes 10 items concerning general health-related behaviors (diet, exercise, follow-up, prevention of infections) and measuring their frequency (from 1 - never to 5 - always). The symptom perception domain comprises 9 items regarding the frequency of heart failure symptoms (dyspnea, edema, weight gain, fatigue, etc.) and 2 items to determine how quickly the patient noticed the symptoms and identified them as heart failure-related. For these 2 items, the responses range from "not applicable" (no symptoms) or 0 (did not recog- 
nize the symptom) to 5 (recognized the symptom very quickly). The self-care management domain is composed of 8 items. Seven of them rate how likely the respondent is to try the behaviors commonly used to control heart failure symptoms ( 1 - unlikely, 5 - very likely). One item asks the patient how sure they are that the treatment most recently used to manage their symptoms helped them. Responses here range from 0 (I did nothing) or 1 (not sure) to 5 (very sure). Scores are standardized to a value between 0 and 100 points, and higher scores indicate a higher level of self-care [13].

The questionnaire is available in many language versions, but validation studies have so far been completed with heart failure patients from the United States and Italy [13,v15]. The Polish version of the question-

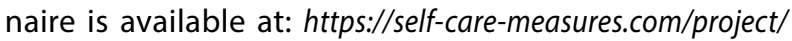
patient-version-schfi-polish-7-2/.

\section{Translation and adaptation procedure}

In accordance with the widely accepted standard methodology [17], the questionnaire validation procedure comprised obtaining consent from the questionnaire's author, Barbara Riegel, establishing an expert committee, forward translation from English into Polish, synthesis of translation, backward translation, expert committee review and preliminary pilot testing.

Translation of the Revised SCHFI (v 7.2) into Polish was performed by a team of specialists ( 2 physicians and 2 nurses) fluent in both languages, whose native language was Polish. The text was then discussed and corrected by a team of medical specialists (1 physician and 1 nurse), and the corrected version was sent to a translation agency. Once the translated text had been proofread by the translation agency, the final suggested version was submitted to an expert panel for approval. The resulting Polish version was submitted to an independent team of medical professionals fluent in both Polish and English, whose native language was English, to translate the text back into English (back translation). After a discussion between designated experts and a number of minor corrections regarding style, the resulting text was officially approved. The back-translated English version of the translated questionnaire was submitted to the author for approval (backward-forward translation).

After the translation was approved by the author of the original version, a pilot study was conducted to verify patients' understanding of the Polish version of the questionnaire. The pilot study included 16 heart failure patients of a cardiology clinic. All patients filled in the questionnaire on their own and did not report any difficulties in understanding or responding to any of the items. The pretested version of the Revised SCHFI was used as the final version for psychometric tests in a population of patients with heart failure in Poland.

\section{Ethical considerations}

The study was approved by the local Bioethics Committee (approval no. KB 67/2016). Written informed consent was obtained from each participant prior to their inclusion, and the investigation conformed to the principles outlined in the Declaration of Helsinki. Data confidentiality was assured by using assigned code numbers in lieu of participants' names.

\section{Statistical analysis}

Internal consistency was evaluated using Cronbach's a and confirmatory factor analysis. In the latter, model fit was assessed using $\mathrm{Hu}$ and Bentler's two-index method. As SCHFI items are expressed on an ordinal scale, and not a continuous one, parameter estimation was performed using Diagonally Weighted Least Squares. The convergent validity of the instrument was assessed by correlating SCHFI and EHFSc-9 scores. All analyses used a significance threshold of 0.05 , i.e. all $P$ values of less than 0.05 were interpreted as showing significant associations. The analyses were performed using the R software, version 3.6.0 [18]. The distribution of the analyzed variables was non-normal (this was verified by the Shapiro-Wilk test) and therefore the Mann-Whitney and Kruskalla-Wallis tests and the Spearman correlation coefficient were used.

The minimum sample size was determined based on specific parameters (estimated fraction size, maximum error of the estimate, level of statistical significance, and size of general population), and amounted to 119 patients $(P=0.05)$.

\section{RESULTS}

\section{Study participants}

The study included 127 patients with heart failure, at a mean (SD) age of 68.54 (11.16) years (Table 1). Most respondents were male (64.57\%), lived with their spouse (59.05\%), and had completed primary education (43.31\%). The mean (SD) duration of illness was 5.9 (8.48) years. The mean (SD) number of hospitalizations was 1.19 (2.67). The majority of patients were in New York Heart Association (NYHA) functional classes II (42.52\%) and III (37.01\%).

The mean (SD) overall level of self-care measured by the EHFSc-9 in the study group was 51.92 (22.0) (Table 1). Patients obtained the highest Revised SCHFI scores in the self-care confidence domain (mean [SD] scores, 65.63 [21.0] points), and the lowest in symptom perception (54.64 [18.28] points).

\section{Structural validity (dimensionality)}

The original SCHFI has a 3-factor structure. Table 2 shows the fit index values for the SCHFI v. 7.2 model tested. Item loadings ranged between 0.217 and 0.793 and were statistically significant $(P<0.05)$, with the exception of item 3 of 
Table 1. Socio-demographic and clinical characteristics of the study group

\begin{tabular}{|c|c|c|}
\hline \multicolumn{2}{|l|}{ Variables } & Total $(n=127)$ \\
\hline Age, years, mean (SD) & & $68.54(11.16)$ \\
\hline $\begin{array}{l}\text { Gender } \\
\text { Female } \\
\text { Male }\end{array}$ & & $\begin{array}{l}45(35.43) \\
82(64.57)\end{array}$ \\
\hline $\begin{array}{l}\text { The person patient live with } \\
\text { With spouse } \\
\text { In the care home } \\
\text { With children/other family } \\
\text { Alone }\end{array}$ & & $\begin{array}{l}75(59.05) \\
2(1.58) \\
20(15.75) \\
30(23.62)\end{array}$ \\
\hline $\begin{array}{l}\text { Education } \\
\text { Primary } \\
\text { High School } \\
\text { University }\end{array}$ & & $\begin{array}{l}55(43.31) \\
42(33.07) \\
30(23.62)\end{array}$ \\
\hline Heart failure duration, year, me & $n(S D)$ & $5.9(8.48)$ \\
\hline LVEF, mean (SD) & & $44.21(12.72)$ \\
\hline $\begin{array}{c}\text { NYHA } \\
\text { I } \\
\text { II } \\
\text { III } \\
\text { IV }\end{array}$ & & $\begin{array}{c}16(12.60) \\
54(42.52) \\
47(37.01) \\
10(7.87)\end{array}$ \\
\hline $\begin{array}{l}\text { Number of heart failure } \\
\text { hospitalizations, mean (SD) }\end{array}$ & & $1.19(2.67)$ \\
\hline $\begin{array}{l}\text { Medication } \\
\quad \text { Diuretics } \\
\beta \text {-blockers } \\
\text { ACE inhibitors/ARB } \\
\text { Digoxin }\end{array}$ & & $\begin{array}{l}92(72.44) \\
90(70.87) \\
65(51.18) \\
14(11.02)\end{array}$ \\
\hline $\begin{array}{l}\text { Comorbidities } \\
\text { Diabetes } \\
\text { Asthma } \\
\text { Coronary artery disease } \\
\text { Chronic obstructive pulmon } \\
\text { Renal failure } \\
\text { Hypertension }\end{array}$ & ry disease & $\begin{array}{c}53(41.73) \\
4(3.15) \\
34(26.77) \\
10(7.87) \\
18(14.17) \\
104(81.89)\end{array}$ \\
\hline Questionnaire & Mean (SD) & Median (IQR) \\
\hline EHFSCBS-9 & $51.92(22.0)$ & $50.0(43.75-68.75)$ \\
\hline $\begin{array}{l}\text { SCHFI: Self-care maintenance } \\
\text { Me (SD) }\end{array}$ & $56.24(19.83)$ & $57.5(44.57-67.39)$ \\
\hline SCHFI: Symptom perception & $54.64(18.28)$ & $54.35(45.45-71.21)$ \\
\hline SCHFI: Self-care management & $57.86(19.89)$ & $54.55(55.00-80.00)$ \\
\hline SCHFI: Self-care confidence & $65.63(21.0)$ & $65.0(36.11-66.67)$ \\
\hline
\end{tabular}

Abbreviations: $A C E$, angiotensin-converting enzyme; $A R B$, angiotensin receptor blocker; EHFSCBS-9, European Heart Failure Self-Care Behavior Scale; LVEF, left ventricular ejection fraction; N, number of patients; NYHA, New York Heart Association; Q1, first quartile; Q3, third quartile; SCHFI, Self-Care of Heart Failure Index; SD, standard deviation

the consulting behaviors scale ("Eat a low-salt diet"; 0.087; $P=0.56$ ) (Table 3).

Table 3 presents the descriptive analysis of SCHFI v 7.2 items. On the self-care maintenance scale, the item with the highest score was item 1, "Try to avoid getting sick", and the one with the lowest score was item 7, "Make sure to get a flu shot annually". Regarding the symptom perception scale, the item with the highest score was item 15, "Ask your healthcare provider how you're doing". The item with the lowest score was item 19, “Keep a record of symptoms". In the self-care management scale, the item with the highest score was item 28, "Limit your activity until you feel better", and the one with the lowest score was item 22, "Further limit the salt you eat that day".

The Revised SCHFI had satisfactory psychometric properties in all subscales: self-care maintenance $\alpha=0.790$, symptom perception $a=0.790$, self-care management $a=0.705$.

\section{Theoretical (convergent) validity - analysis of correlations between SCHFI and EHFSc-9}

The EHFSc-9 questionnaire is used to assess the self-care capabilities of patients with heart failure. In the study, its score was inverted and standardized. As interpreted by the questionnaire's authors, a patient can score between 0 and 100 points, with higher scores indicating better self-care [15]. The mean (SD) EHFSc-9 score was 51.92 (22.0) points out of 100 .

EHFSC- 9 is significantly $(P<0.05)$ and positively correlated with the self-care maintenance, symptom perception, and self-care management scales of the Revised SCHFI (Table 4), but no statistically significant correlation was found with self-care confidence $(P=0.18)$.

Statistically significant differences were observed in self-care maintenance based on left ventricular ejection fraction (LVEF) over $40 \%$ and NYHA class (Table 5). No statistically significant differences existed for the other variables.

\section{DISCUSSION}

The purpose of this study was to perform the translation and cross-cultural adaptation of the Revised SCHFI into Polish, and to evaluate its inter-observer reliability and temporal stability. The psychometric evaluation of the Polish version of the Revised SCHFI indicates that it is a reliable and valid tool for assessing self-care levels in heart failure patients. To the best of our knowledge, this is only the third study of the psychometric properties of SCHFI v. 7.2.

Cross-cultural validation concentrates on 'whether measures that were originally generated in one culture are applicable, meaningful, and thus equivalent in another culture' [19]. In the cross-cultural adaptation process for the Polish version, upon consultation with the author of the original version, items 12, 15, 18, 19, 24, 34 were modified for ease of understanding and to facilitate administration, and were subsequently approved by the author.

The Polish version of the SCHFI is internally consistent $[20,21]$. So far, the Italian version of the SCHFI has also

Table 2. Fit indices of the tested SCHFI v. 7.2 model

\begin{tabular}{l|c|c|c|c|cc|cc}
\multicolumn{1}{c|}{ Subscale } & $\mathbf{X}$ & df & P-value & RMSEA & CFI & TLI & SRMR \\
Self-care maintenance & 45.832 & 33 & 0.07 & 0.056 & 0.971 & 0.96 \\
Symptom perception & 28.456 & 42 & 0.95 & $<0.01$ & $>0.99$ & $>0.99$ \\
Self-care management & 14.916 & 19 & 0.73 & $<0.01$ & $>0.99$ & $>0.99$ \\
\hline
\end{tabular}

Abbreviations: $\mathrm{X} 2$, Chi-square test; $\mathrm{CFI}$, comparative fit index; df, degree of freedom; RMSEA, root mean square error of approximation; SRMR, standardized root mean square residual; TLI, Tucker and Lewis Index 
Table 3. The revised SCHFI structure and loadings for each item of the SCHFI questionnaire

\begin{tabular}{|c|c|c|c|c|c|c|}
\hline Subscale & Item & Mean (SD) & Skewness & Kurtosis & Loading & $P$-value \\
\hline \multicolumn{7}{|l|}{ Self-care maintenance } \\
\hline \multirow[t]{8}{*}{ Consulting behaviors } & 1 & $4.19(1.10)$ & -1.50 & 4.71 & 0.459 & $<0.001$ \\
\hline & 2 & $3.31(1.33)$ & -0.25 & 1.99 & 0.520 & $<0.001$ \\
\hline & 3 & $3.44(1.41)$ & -0.44 & 1.98 & 0.087 & 0.56 \\
\hline & 4 & $4.52(1.05)$ & -2.43 & 7.92 & 0.425 & $<0.001$ \\
\hline & 5 & $4.46(1.13)$ & -2.21 & 6.80 & 0.456 & $<0.001$ \\
\hline & 7 & $1.77(1.35)$ & 1.54 & 3.87 & 0.306 & 0.01 \\
\hline & 9 & $2.17(1.55)$ & 0.87 & 2.13 & 0.571 & $<0.001$ \\
\hline & 10 & $3.36(1.45)$ & -0.29 & 1.74 & 0.726 & $<0.001$ \\
\hline \multirow[t]{3}{*}{ Dietary behaviors } & 3 & $3.44(1.41)$ & -0.44 & 1.98 & 0.485 & $<0.001$ \\
\hline & 6 & $2.67(1.52)$ & 0.26 & 1.63 & 0.735 & $<0.001$ \\
\hline & 8 & $2.61(1.49)$ & 0.33 & 1.75 & 0.877 & $<0.001$ \\
\hline \multicolumn{7}{|l|}{ Symptom perception } \\
\hline \multirow[t]{9}{*}{ Monitoring behaviors } & 11 & $2.52(1.41)$ & 0.40 & 1.93 & 0.391 & $<0.001$ \\
\hline & 12 & $3.56(1.19)$ & -0.50 & 2.56 & 0.557 & $<0.001$ \\
\hline & 13 & $3.26(1.39)$ & -0.29 & 1.90 & 0.516 & $<0.001$ \\
\hline & 14 & $3.75(1.11)$ & -0.69 & 3.00 & 0.478 & $<0.001$ \\
\hline & 15 & $3.87(1.29)$ & -0.90 & 2.71 & 0.488 & $<0.001$ \\
\hline & 16 & $3.65(1.15)$ & -0.46 & 2.30 & 0.773 & $<0.001$ \\
\hline & 17 & $3.72(1.34)$ & -0.79 & 2.49 & 0.692 & $<0.001$ \\
\hline & 18 & $3.65(1.36)$ & -0.65 & 2.14 & 0.570 & $<0.001$ \\
\hline & 19 & $1.74(1.23)$ & 1.58 & 4.36 & 0.356 & $<0.001$ \\
\hline \multirow[t]{2}{*}{ Symptom recognition } & 20 & $2.35(1.66)$ & -0.01 & 1.92 & 0.843 & $<0.001$ \\
\hline & 21 & $1.99(1.74)$ & 0.37 & 1.82 & 0.920 & $<0.001$ \\
\hline \multicolumn{7}{|l|}{ Self-care management } \\
\hline \multirow[t]{5}{*}{ Recommended behaviors } & 22 & $1.99(1.74)$ & 0.37 & 1.82 & 0.511 & $<0.001$ \\
\hline & 23 & $2.93(1.53)$ & 0.08 & 1.65 & 0.514 & $<0.001$ \\
\hline & 24 & $2.70(1.39)$ & 0.26 & 1.94 & 0.475 & $<0.001$ \\
\hline & 29 & $3.20(1.70)$ & -0.64 & 2.10 & 0.517 & $<0.001$ \\
\hline & 25 & $3.28(1.50)$ & -0.25 & 1.67 & 0.607 & $<0.001$ \\
\hline \multirow[t]{3}{*}{ Problem solving behaviors } & 26 & $3.11(1.49)$ & -0.17 & 1.69 & 0.589 & $<0.001$ \\
\hline & 27 & $3.21(1.20)$ & -0.14 & 2.39 & 0.654 & $<0.001$ \\
\hline & 28 & $3.59(1.23)$ & -0.41 & 2.25 & 0.237 & 0.03 \\
\hline
\end{tabular}

been validated. In the own study, to assess the internal consistency of the questionnaire, Cronbach's a was determined for all domains of the SCHFI questionnaire [22]. The Cronbach's a values for the self-care maintenance and symptom perception subscales here were similar to those found in the original and Italian versions (respectively, self-care maintenance -0.790 vs 0.710 vs 0.733 ; symptom perception -0.790 vs 0.810 vs 0.830$)[13,15]$. The greatest difference in Cronbach's a was found for the self-care management domain, where the original version of the questionnaire had a considerably lower value of this reliability index (0.660), compared to the Polish (0.705) and Italian versions $(0.802)[13,15]$. The results of confirmatory factor analysis confirmed the three-factor structure of the questionnaire. The fit measure values obtained by Riegiel et al. [13] confirmed that the revised self-care theory including self-care maintenance, symptom perception, and self-care management is an accurate representation of the way self-care processes occur in patients with heart failure. Our analysis also supported the structural validity of the scale. All items had statistically significant loadings, with the exception of item 3 in the consulting behaviors scale ("Eat a low-salt diet"). Similarly, in the study by Vellone et
Table 4. Spearman rank correlation coefficients

\begin{tabular}{l|c}
\multicolumn{1}{c|}{ SCHFI } & EHFScBS-9 \\
\cline { 2 - 2 } & Spearman correlation coefficient \\
Self-care maintenance & $r=0.344 ; P<0.001^{\mathrm{a}}$ \\
Symptom perception & $r=0.241 ; P=0.01^{\mathrm{a}}$ \\
Self-care management & $\mathrm{r}=0.241 ; \mathrm{P}=0.01^{\mathrm{a}}$ \\
Self-care confidence & $\mathrm{r}=0.119 ; \mathrm{P}=0.18$ \\
\hline
\end{tabular}

aStatistically significant correlation $(P<0.05)$. EHFSCBS-9 revised into a nine-item scale; $r$, correlation coefficient.

Abbreviations: see Table 1

al. [15], all loadings except for item 2 ("Get some exercise") were statistically significant.

Polish patients obtained the highest scores in self-care confidence, and the lowest in symptom perception, while the overall self-care level measured using the EHFSc-9 was similar to that obtained in the study by Uchmanowicz and Wleklik [23] on a group of Polish patients with heart failure. Notably, though, self-care capabilities may be affected by differences between the health care systems of each country, as well as socio-economic conditions [13, 15]. Our analysis demonstrated that patients with higher selfcare scores on the self-care maintenance and symptom 
Table 5. Results of correlation analysis of sociodemographic and clinical variables with domains of the SCHFI questionnaire

\begin{tabular}{|c|c|c|c|c|c|c|c|}
\hline \multicolumn{2}{|r|}{ Variables } & \multicolumn{6}{|c|}{ SCHFI } \\
\hline & & \multicolumn{2}{|c|}{ Self-care maintenance } & \multicolumn{2}{|c|}{ Symptom perception } & \multicolumn{2}{|c|}{ Self-care management } \\
\hline & & Mean (SD) & P-value & Mean (SD) & P-value & Mean (SD) & $P$-value \\
\hline \multirow[t]{2}{*}{ Age, years } & $<65(n=46)$ & $54.13(19.33)$ & 0.33 & $55(16.65)$ & 0.94 & $54.48(21.39)$ & 0.33 \\
\hline & $>65(n=81)$ & $57.44(20.13)$ & & $54.44(19.24)$ & & $59.78(18.85)$ & \\
\hline \multirow[t]{2}{*}{ Gender } & Female $(n=45)$ & $53.06(18.46)$ & 0.18 & $54.11(17.13)$ & 0.76 & $57.38(16.92)$ & 0.77 \\
\hline & Male $(n=82)$ & $57.99(20.45)$ & & $54.93(18.98)$ & & $58.13(21.44)$ & \\
\hline \multirow{4}{*}{$\begin{array}{l}\text { The person patient } \\
\text { live with }\end{array}$} & With spouse $(n=61)$ & $58.73(21.09)$ & 0.56 & $54.6(18.74)$ & 0.86 & $58.02(20.2)$ & 0.53 \\
\hline & With spouse/children/other family $(n=14)$ & $51.61(19.03)$ & & $51.88(20.95)$ & & $59.31(24.81)$ & \\
\hline & With children/other family $(n=20)$ & 55 (20.15) & & $54.37(16.37)$ & & $60.76(17.27)$ & \\
\hline & In the care home or alone $(n=32)$ & $54.3(17.62)$ & & $56.1(18.01)$ & & $55.12(19.05)$ & \\
\hline \multirow[t]{3}{*}{ Education } & Primary $(n=55)$ & $52.5(21.35)$ & 0.08 & $51.22(14.41)$ & 0.18 & $56.03(18.32)$ & 0.44 \\
\hline & High school $(n=42)$ & $56.37(17.51)$ & & $56.53(20.4)$ & & $56.64(19.66)$ & \\
\hline & University $(\mathrm{n}=30)$ & $62.92(18.8)$ & & $58.26(20.88)$ & & $62.93(22.63)$ & \\
\hline \multirow{2}{*}{$\begin{array}{l}\text { Heart failure duration, } \\
\text { years }\end{array}$} & $<5(n=87)$ & $57.24(19.12)$ & 0.20 & $53.62(18.01)$ & 0.39 & $57.16(20.07)$ & 0.56 \\
\hline & $>5(n=40)$ & $54.06(21.38)$ & & $56.86(18.89)$ & & $59.39(19.66)$ & \\
\hline \multirow[t]{2}{*}{ LVEF } & $<40 \%(n=55)$ & $50.86(20.64)$ & $0.03^{\mathrm{a}}$ & $50.96(18.12)$ & $0.04^{\mathrm{a}}$ & $53.66(21.72)$ & 0.07 \\
\hline & $>40 \%(n=72)$ & $60.35(18.29)$ & & $57.45(18.02)$ & & $61.07(17.86)$ & \\
\hline \multirow[t]{3}{*}{ NYHA } & $I, I / I I(n=19)$ & $57.63(19.68)$ & $0.01^{\mathrm{a}}$ & $50.77(20.52)$ & 0.44 & $59.81(20.72)$ & \\
\hline & $\|,\| / I I I(n=58)$ & $60.91(19.66)$ & & $57.06(16.78)$ & & $60.92(20.18)$ & 0.11 \\
\hline & III, III/IV, IV (n= 50) & $50.3(18.9)$ & & $53.31(19.04)$ & & $53.58(18.82)$ & \\
\hline \multirow{2}{*}{$\begin{array}{l}\text { Heart failure hospita- } \\
\text { lizations }\end{array}$} & $0-1(n=95)$ & $56.45(19.16)$ & $0.79^{a}$ & $53.71(18.15)$ & 0.31 & $58.44(18.6)$ & 0.73 \\
\hline & $>1(n=32)$ & $55.62(22.02)$ & & $57.4(18.66)$ & & $56.16(23.55)$ & \\
\hline
\end{tabular}

aStatistically significant correlation $(P<0.05)$.

Abbreviations: see Table 1

perception subscales had a higher LVEF and lower NYHA class. In the literature, the discussion on the impact of clinical factors, including NYHA class and LVEF, on self-care and quality of life in heart failure patients is ongoing $[24,25]$. In the study by Kamrani et al. [24], LVEF above $40 \%$ and lower NYHA class were identified as independent determinants of self-care in heart failure patients.

Our study also verified the theoretical validity of the instrument. In correlation analysis, SCHFI v. 7.2 was significantly correlated with EHFSc-9, though no statistically significant correlations were found for the self-care confidence domain. This warrants the conclusion that EHFSc-9 is not a suitable instrument for evaluating heart failure patients' self-care confidence. On the other hand, the author of the original questionnaire points out that the questionnaire provides an additional rating of self-care confidence, which is not a component of self-care, but has a powerful influence on it.

\section{Study limitations}

The study had a number of limitations. One is the use of convenience sampling. Another is the small sample size, which could make our estimates unstable. Questionnaire scores, which reflect the patients' subjective assessment, were not compared with any other parameters than NYHA class or LVEF. The last limitation results from not using the global reliability index for multidimensional scales.

\section{Practical implications}

The Revised SCHFI is a simple research tool that can be used to systematically evaluate the self-care capabilities of pa- tients with heart failure and can be used alongside clinical parameters. The results obtained using this questionnaire can be a valuable source of information on the effectiveness of educational activities undertaken within multidisciplinary management programs. Moreover, due to the satisfactory psychometric properties in many countries, it may become a common tool used in cross-cultural research.

\section{CONCLUSION}

Psychometric evaluation of the Polish version of the Revised $\mathrm{SCHFI}$ indicates that it is a reliable and valid measurement tool to assess the self-care level of heart failure patients. The Revised SCHFI may be routinely used to control patients with heart failure and support communication about the self-care education and behavior in heart failure patients in clinical practice.

\section{Article information}

Acknowledgments: The publication was prepared under the project financed from the funds granted by the Ministry of Science and Higher Education in the "Regional Initiative of Excellence" program for the years 2019-2022, project number 016/RID/2018/19.

Conflict of interest: None declared.

Open access: This article is available in open access under Creative Common Attribution-Non-Commercial-No Derivatives 4.0 International (CC BY-NC-ND 4.0) license, allowing to download articles and share them with others as long as they credit the authors and the publisher, but without permission to change them in any way or use them commercially. For commercial use, please contact the journal office at kardiologiapolska@ptkardio.pl.

How to cite: Świątoniowska-Lonc N, Polański J, Pilarczyk-Wróblewska I, et al. The Revised Self-Care of Heart Failure Index - a new tool for 
assessing the self-care of Polish patients with heart failure. Kardiol Pol. 2021; 79(7-8): 841-847, doi: 10.33963/KP.a2021.0009.

\section{REFERENCES}

1. Ziaeian B, Fonarow GC. Epidemiology and aetiology of heart failure. Nat Rev Cardiol. 2016; 13(6):368-378, doi: 10.1038/nrcardio.2016.25, indexed in Pubmed: 26935038.

2. Bui AL, Horwich TB, Fonarow GC. Epidemiology and risk profile of heart failure. Nat Rev Cardiol.2011;8(1):30-41, doi: 10.1038/nrcardio.2010.165, indexed in Pubmed: 21060326.

3. Loghmani L, Monfared M. The effect of self-care education on knowledge and function of patients with heart failure hospitalized in Kerman city hospitals in (2017). Electron J Gen Med. 2018; 15(4), doi: 10.29333/ejgm/85684.

4. Navidian A, Yaghoubinia F, Ganjali A, et al. The effect of self-care education on the awareness, attitude, and adherence to self-care behaviors in hospitalized patients due to heart failure with and without depression. PLoS One. 2015; 10(6): e0130973, doi: 10.1371/journal.pone.0130973, indexed in Pubmed: 26091101.

5. Smeulders ES, van Haastregt JCM, van Hoef EFM, et al. Evaluation of a self-management programme for congestive heart failure patients: design of a randomised controlled trial. BMC Health Serv Res. 2006; 6: 91, doi: 10.1186/1472-6963-6-91, indexed in Pubmed: 16857049.

6. Pieske B, Tschöpe C, de Boer RA, et al. 2016 ESC Guidelines for the diagnosis and treatment of acute and chronic heart failure: The Task Force for the diagnosis and treatment of acute and chronic heart failure of the European Society of Cardiology (ESC)Developed with the special contribution of the Heart Failure Association (HFA) of the ESC. Eur Heart J. 2016; 37(27): 2129-2200, doi: 10.1093/eurheartj/ehw128, indexed in Pubmed: 27206819.

7. Uchmanowicz I, Lisiak $M$, Lelonek $M$, et al. A curriculum for heart failure nurses: an expert opinion of the Section of Nursing and Medical Technicians and the Heart Failure Working Group of the Polish Cardiac Society. Kardiol Pol. 2020; 78(6): 647-652, doi: 10.33963/KP.15405, indexed in Pubmed: 32486627.

8. Koirala B, Dennison Himmelfarb CR, Budhathoki $C$, et al. Heart failure self-care, factors influencing self-care and the relationship with health-related quality of life: A cross-sectional observational study. Heliyon. 2020; 6(2): e03412, doi: 10.1016/j.heliyon.2020.e03412, indexed in Pubmed: 32149197.

9. Self Care of Heart Failure Index-Patient Version. Available online: https:// self-care-measures.com/available-self-care-measures/self-care-of-heartfailure-index-2/. [Last accessed: December 28, 2020]. : 2020

10. Riegel B, Dickson VV. A situation-specific theory of heart failure self-care. J Cardiovasc Nurs. 2008; 23(3): 190-196, doi: 10.1097/01. JCN.0000305091.35259.85, indexed in Pubmed: 18437059.

11. Riegel B, Barbaranelli C, Carlson B, et al. Psychometric testing of the selfcare of heart failure index. J Card Fail. 2004; 10(4):350-360, doi: 10.1016/j. cardfail.2003.12.001, indexed in Pubmed: 15309704.
12. Riegel B, Lee CS, Dickson VV, et al. An update on the self-care of heart failure index. J Cardiovasc Nurs. 2009; 24(6): 485-497, doi: 10.1097/JCN.0b013e3181b4baa0, indexed in Pubmed: 19786884.

13. Riegel B, Barbaranelli C, Carlson B, et al. Psychometric testing of the revised self-care of heart failure index. J Cardiovasc Nurs. 2019; 34(2): 183-192, doi: 10.1097/JCN.0000000000000543, indexed in Pubmed: 30303894.

14. Vellone E, Riegel B, Cocchieri A, et al. Psychometric testing of the self-care of heart failure index version 6.2. Res Nurs Health. 2013; 36(5): 500-511, doi: 10.1002/nur.21554, indexed in Pubmed: 23832431

15. Vellone $E$, De Maria $M$, lovino $P$, et al. The self-care of heart failure index version 7.2: further psychometric testing. Res Nurs Health. 2020; 43(6): 640-650, doi: 10.1002/nur.22083, indexed in Pubmed: 33141495.

16. Vellone $E$, Jaarsma $T$, Strömberg A, et al. The European Heart Failure Self-Care Behaviour Scale: new insights into factorial structure, reliability, precision and scoring procedure. Patient Educ Couns. 2014; 94(1): 97-102, doi: 10.1016/j.pec.2013.09.014, indexed in Pubmed: 24148605.

17. Ozolins U, Hale S, Cheng X, et al. Translation and back-translation methodology in health research - a critique. Expert Rev Pharmacoecon Outcomes Res. 2020;20(1):69-77, doi: 10.1080/14737167.2020.1734453, indexed in Pubmed: 32089017

18. The R. The R Project for Statistical Computing. Available online: www.R-project.org/. [Last accessed: October 20, 2020].

19. Eremenco SL, Cella D, Arnold BJ. A comprehensive method for the translation and cross-cultural validation of health status questionnaires. Eval Health Prof. 2005; 28(2): 212-232, doi: 10.1177/0163278705275342, indexed in Pubmed: 15851774.

20. Wang K, Xu Y, Wang C, et al. A Corrected Goodness-of-Fit Index (CGFI) for Model Evaluation in Structural Equation Modeling. Struct Equ Model. 2019; 27(5): 735-749, doi: 10.1080/10705511.2019.1695213.

21. Sivo S, Fan X, Witta E, et al. The search for "optimal" cutoff properties: fit index criteria in structural equation modeling. The Journal of Experimental Education. 2006; 74(3): 267-288, doi: 10.3200/jexe.74.3.267-288.

22. Tavakol M, Dennick R. Making sense of Cronbach's alpha. Int J Med Educ. 2011; 2: 53-55, doi: 10.5116/ijme.4dfb.8dfd, indexed in Pubmed: 28029643.

23. Uchmanowicz I, WleklikM. Polish adaptation and reliability testing of the nine-item European Heart Failure Self-care Behaviour Scale (9-EHFScBS). Kardiol Pol. 2016; 74(7): 691-696, doi: 10.5603/KP.a2015.0239, indexed in Pubmed: 26620684.

24. Kamrani AAA, Foroughan $M$, Taraghi $Z$, et al. Self care behaviors among elderly with chronic heart failure and related factors. Pak J Biol Sci. 2014; 17(11): 1161-1169, doi: 10.3923/pjbs.2014.1161.1169, indexed in Pubmed: 26027161.

25. Peters-Klimm F, Freund T, Kunz CU, et al. Determinants of heart failure selfcare behaviour in community-based patients: a cross-sectional study. Eur J Cardiovasc Nurs. 2013; 12(2): 167-176, doi: 10.1177/1474515112439964, indexed in Pubmed: 22514139. 